\title{
Improvement of Emissions and Burning Limits in Burner Combustion using an Injector on the Concept of Fuel-Water Internally Rapid Mixing
}

\author{
Tomoaki Yatsufusa ${ }^{1}$, Yoshiyuki Kidoguchi ${ }^{2}$ and Daisuke Nakagawa ${ }^{3}$ \\ 1. Department of Intelligent Mechanical Engineering, Faculty of Engineering, Hiroshima Institute of Technology, Hiroshima \\ 731-5193, Japan \\ 2. Department of Energy System, Institute of Technology and Science, University of Tokushima, Tokushima 770-8506, Japan \\ 3. Graduate School of Advanced Technology and Science, University of Tokushima, Tokushima 770-8506, Japan
}

Received: June 16, 2013 / Accepted: August 06, 2013 / Published: January 31, 2014.

\begin{abstract}
This study tried to apply biomass fuel to clean burner combustion under high load conditions by water addition. A newly developed injector mixes fuel rapidly with water inside of the injector with support of atomizing air. The mixture composed of three-fluid is injected as spray into a flame stabilizer of burner. Investigation of emission performance of this injector shows that the internally rapid mixing type of injector is hopeful technique to introduce water into burner combustion. Combustion by this injector emits exceedingly less particulate matters at high load. $\mathrm{NO}_{\mathrm{x}}$ emission is strongly dependent on water flow rate.
\end{abstract}

Key words: Combustion, low-quality fuel, water addition, emulsified fuel.

\section{Introduction}

The shortage of the energy is now the major concerning matter in worldwide. Because of this, demand for using low quality fuel and waste oil is increasing. In general, these kinds of fuel are favorable for burner combustion rather than other combustion equipment. However, such a low quality fuel usually exhausts more toxic emissions, including $\mathrm{NO}_{\mathrm{x}}, \mathrm{CO}$ and PM (particulate matters), which would cause environmental problems. On the other hand, demand of biomass as fuel is also increasing due to the issue of global warming. However, the biomass fuel is generally low quality for combustion usage, which causes the same problem in toxic emissions. Therefore, reduction of toxic emissions is a key issue to resolve energy shortage and environmental problems

Corresponding author: Tomoaki Yatsufusa, associate professor, research fields: fuel spray, engine combustion and detonation. E-mail: t.yatsufusa.nr@cc.it-hiroshima.ac.jp. simultaneously.

Water-emulsification has been well known as one of easy and low cost solutions for reducing toxic emissions in burner combustion. Water-emulsified fuel lowers flame temperature, leading to $\mathrm{NO}_{\mathrm{x}}$ reduction; furthermore, it reduces PM emissions [1-5]. One reason of the reduction in PM is micro-explosion [6-8], the rapid boiling of water introduced into the flame by high temperature. Micro-explosion promotes fuel atomization and results in PM reduction. The other reason is hydro-gaseous reaction that converts solid carbons and water into carbon monoxide and hydrogen.

However, water-emulsification needs surfactant to mix fuel and water, and to avoid separation of them. Although adding surfactant, water-emulsified fuel still has disadvantage in temporal stability as fuel. Furthermore, the additional cost of surfactant spoils the cost performance of low quality fuels. It is indispensable to find the effective way to introduce the 

Injector on the Concept of Fuel-Water Internally Rapid Mixing

water into the combustion field without water-emulsification.

Other important thing for energy conservation is to improve heat transfer efficiency in burner combustion. The burner is often applied to a boiler in which thermal energy is conducted into water pipe. In the heat conduction process, some part of thermal energy is lost by exhaust gas. Hence, reduction of exhaust gas flow rate is one of effective idea of improving thermal efficiency in boiler. As for a burner, lower gas flow rate with keeping same fuel burning rate corresponds to high load combustion, namely combustion in high equivalence ratio or low air-fuel ratio; while, the high load combustion results in increase of $\mathrm{NO}_{\mathrm{x}}, \mathrm{PM}$ and CO emissions [5].

This study tries to apply biomass fuel to high-load burner combustion with lower toxic emissions by introduction of water into the flame. Water is introduced into the flame independently from fuel by newly developed burner nozzle. This concept is one of the solutions of both energy conservation and environmental protection.

In this paper, a new injector that can introduce water directly into combustion field will first be explained. The new injector is a type of fuel-water internally rapid mixing. Fuel and water are injected independently into the small mixing chamber and are forced mixing by atomization air in it. After mixing, the mixture is injected from the chamber. In this way, water is introduced directly into combustion field.

The emission characteristics of this injector will be next compared with an existing injector; moreover, the emission performance will be investigated in detail.

\section{Fuel-Water Internally Rapid Mixing Type of Injector}

The configuration of a newly developed injector will be explained first. Fig. 1a shows detail of the injector in cross sectional view and photographs. This injector was named "fuel-water internally rapid mixing type of injector”. Fuel and water are separately and independently supplied to a small mixing chamber inside of the injector. The mixing chamber has a capacity of $3.9 \mathrm{~mL}$. Fuel is supplied from a ring-shaped slit with an outer-diameter of $5.5 \mathrm{~mm}$ and slit-width of $0.45 \mathrm{~mm}$. Water is supplied from a center hole with diameter of $2.0 \mathrm{~mm}$. The supplied fuel and water are rapidly mixed in the mixing chamber with support of atomizing air. The atomizing air is pressurized about $0.2 \mathrm{MPa}$ and introduced into the mixing chamber through four slits of swirler as shown in the picture. The air-flow generates swirl flow in the mixing chamber to improve mixing. The well-mixed fluids; fuel, air and water are injected into combustion field

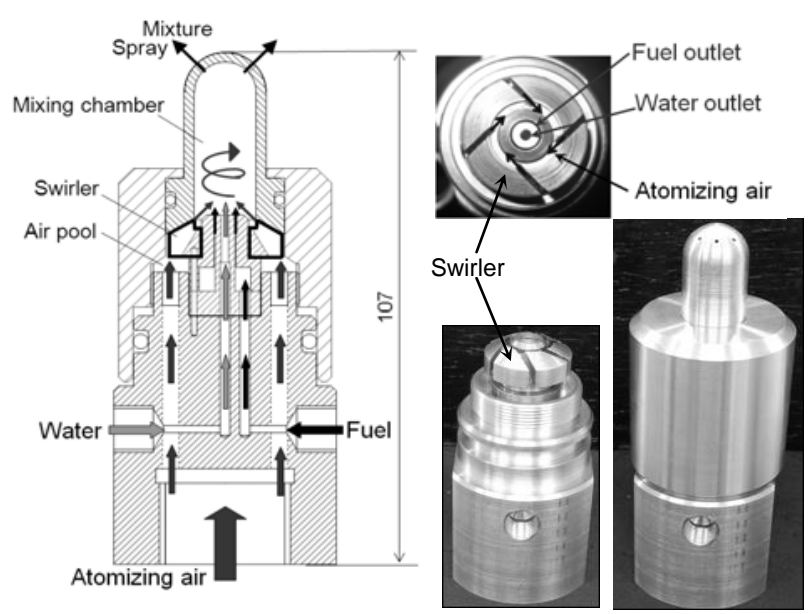

(a) Fuel-water internally rapid mixing type

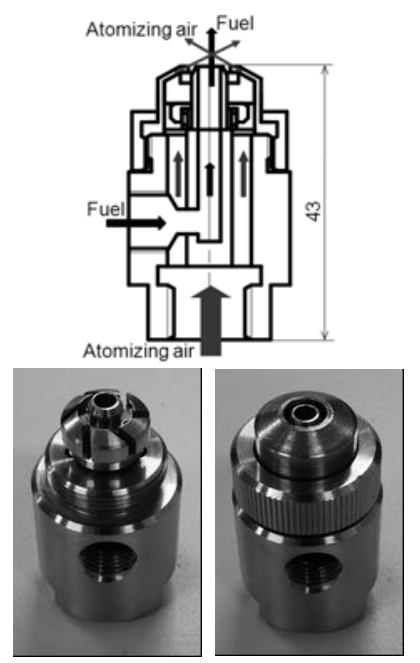

(b) External mixing type

Fig. 1 Configuration of injector. 
from eight small holes with diameter of $1 \mathrm{~mm}$ on the top of the mixing chamber. The advantage of using this injector is that water can be introduced into the combustion field without emulsification process of fuel and water. Therefore, using this injector eliminates the need for the surfactant that is essential for water-emulsified fuel. Furthermore, this injector can feed water without increase of fuel viscosity compared with feeding water by fuel-water emulsification. The fuel-water emulsified fuel often makes inconvenient influence on combustion by increase of fuel viscosity. Another advantage is that, unlike water-emulsified fuel, optimal water content in response to combustion condition can be easily obtained by changing water flow rate.

Fig. $1 \mathrm{~b}$ is an external mixing type of injector, which is generally used in burner. Fuel and air are separately injected from the injector. The injector has the same swirler as the above developed injector to form swirl flow of atomizing air. This injector needs emulsified fuel when water is introduced. Emission characteristics of this injector will be compared with that of the internally rapid mixing type of injector.

\section{Experimental Setup}

Fig. 2 shows schematic diagram of experimental setup. The burner consists of an injector, flame stabilizer, pilot flame igniter and a chimney. The chimney has a height of $700 \mathrm{~mm}$. The flame stabilizer consists of inner and outer tubes as shown in the lower drawing. The inner tube has an inner-diameter of 96.4 $\mathrm{mm}$ and height of $143 \mathrm{~mm}$ from injector outlet. The outer tube has an inner-diameter of $120 \mathrm{~mm}$. Fuel, atomizing air and water supplied separately to the injector are mixed in the injector in the case of the internally rapid mixing type injector. The injected fluids are further mixed with a part of secondary air in the flame stabilizer. The secondary air is supplied into the flame stabilizer through several small holes with diameter of $3 \mathrm{~mm}$. The holes are located at the base and lower part of the side face of the inner tube. Some of

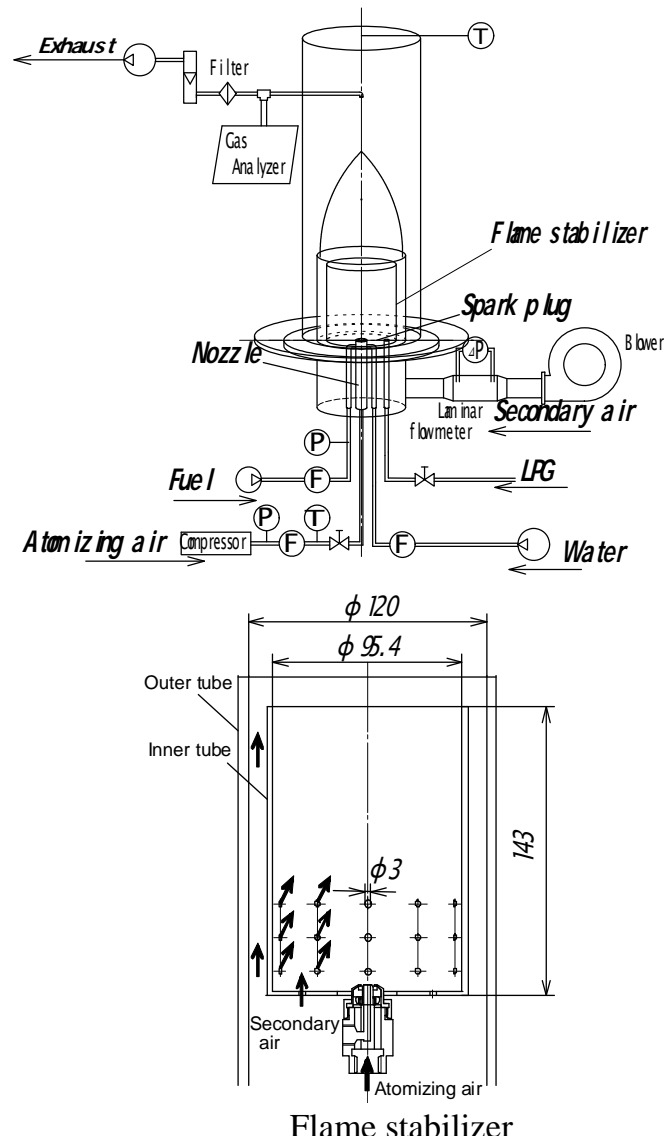

Fig. 2 Experimental apparatus and geometry of burner.

secondary air flow through the gap between inner and outer tubes and supply oxygen to the flame at the upper region of the flame stabilizer.

At first, the burner is ignited and supported by LPG flame until the burner combustion getting stable. After sufficient warming up, exhaust gas from the burner was analyzed to measure the components and temperature. A part of exhaust gas was sampled by a water-cooled sampling probe with suction hole-diameter of $0.5 \mathrm{~mm}$ and introduced into the portable gas analyser (HORIBA, PG-240). The concentration of $\mathrm{NO}_{\mathrm{x}}$ was measured by CLD (chemiluminescent) method, $\mathrm{CO}$ and $\mathrm{CO}_{2}$ by NDIR (non-dispersive infrared) method, and $\mathrm{O}_{2}$ by zirconia method. Exhausted PM was filtered by Teflon sampling filter. The PM concentration was determined by the sampling filter weight difference before and after sampling. PM was divided into two components, 
SOLID (solid carbon) and SOF (soluble organic fraction), by Soxhlet extraction method. SOLID is the main component in smoke and SOF is mainly composed of unburned fuel components. The gas temperature, $T_{700}$, was measure at $700 \mathrm{~mm}$ downstream from the injector.

The controllable parameters in the experiment were fuel type, mass flow rates of fuel $Q_{f}$, atomizing air $Q_{a}$, secondary air $Q_{2}$ and water $Q_{w}$. In the series of experiments, the total air flow rate $Q_{t}\left(=Q_{a}+Q_{2}\right)$ is kept constant at $15.72 \mathrm{~kg} / \mathrm{h}$. Fuel used was soybean oil representative as biomass fuel. Gas oil was also used as reference. The density and kinetic viscosity of soybean oil were $892 \mathrm{~kg} / \mathrm{m}^{3}$ and $74.78 \mathrm{~mm}^{2} / \mathrm{s}$, and gas oil 824 $\mathrm{kg} / \mathrm{m}^{3}$ and $4.08 \mathrm{~mm}^{2} / \mathrm{s}$. Soybean oil contains 11 mass $\%$ of oxygen.

\section{Results and Discussion}

\subsection{Advantage of Fuel-Water Internally Rapid Mixing} Type of Injector

In the experiment, emission characteristics of the two injectors were firstly investigated.

Fig. 3 compares the emissions in the case of burning pure soybean oil without water. The air condition of the burner; namely, mass flow ratio of atomizing air to total air, $Q_{a} / Q_{t}$, is kept constant at 0.26 . In the figure, equivalence ratio $\phi$ is defined based on the mass flow rate of fuel to that of total air including atomizing air and secondary air. As seen from the figure, $\mathrm{NO}_{\mathrm{x}}$ emission is almost same level with both injectors. Lower CO emission by using internally rapid mixing injector than by external mixing injector indicates that the former type injector has better combustion efficiency. At high load condition of $\phi>0.8$, both injectors produce PM that is mainly composed of SOLID. The internally rapid mixing type of injector emits less PM as compared with the external mixing type. Considering that the SOLID is produced by incomplete combustion, fuel-air mixing is promoted by the internally rapid mixing and leads to less SOLID emission. Temperature $T_{700}$ is affected by conditions of

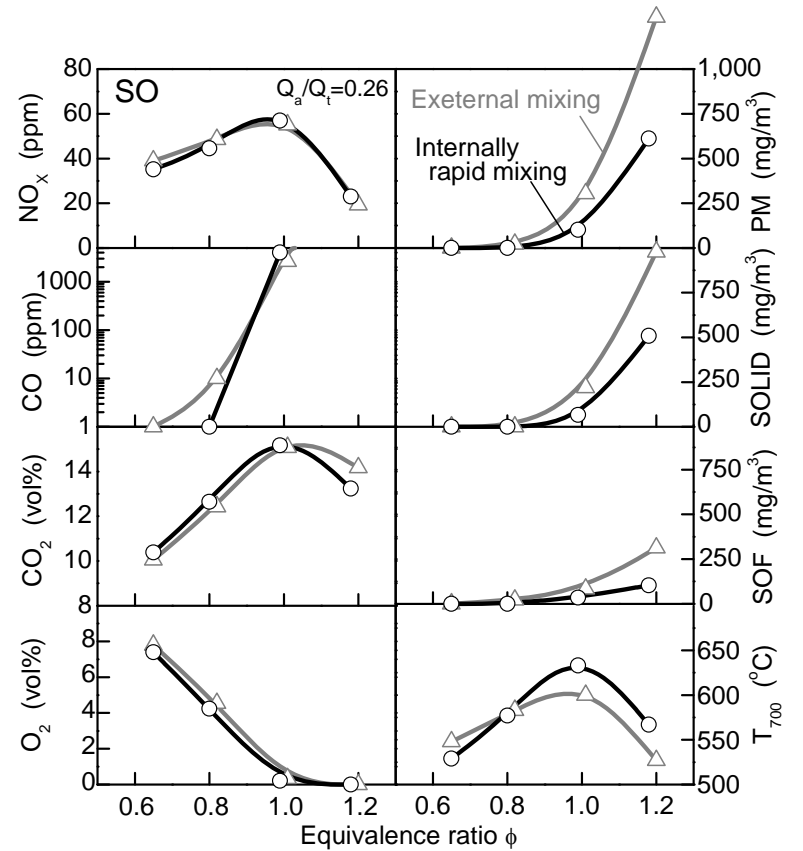

Fig. 3 Comparison of emissions between two types of injector (fuel : soybean without water).

combustion and flame height. In this case, higher gas temperature of $T_{700}$ in the case of internally rapid mixing type is considered the result of better fuel-air mixing.

Fig. 4 is the same comparison of emissions as Fig. 3 when water is introduced into combustion. The external mixing type of injector applies water-emulsified soybean oil as fuel, and internally rapid mixing type of injector mixes soybean oil and water by atomizing air inside of the injector. Water content is $50 \%$ in volume. As compared with Fig. 3, $\mathrm{NO}_{\mathrm{x}}$ is reduced with the use of water in both water-emulsified and water mixing; further, PM is reduced dramatically at high load condition by using water. Both show smokeless combustion at wide range of equivalence ratio. Effects of water will be discussed later again. As compared with the two injectors, external mixing type that uses water-emulsified fuel shows high $\mathrm{CO}$ emission in the whole load condition. This type also produces higher SOF emission than internally rapid mixing type. These results suggest that external mixing type leads incomplete combustion and deterioration of combustion efficiency. Considering the incomplete combustion, higher gas temperature of 

Injector on the Concept of Fuel-Water Internally Rapid Mixing

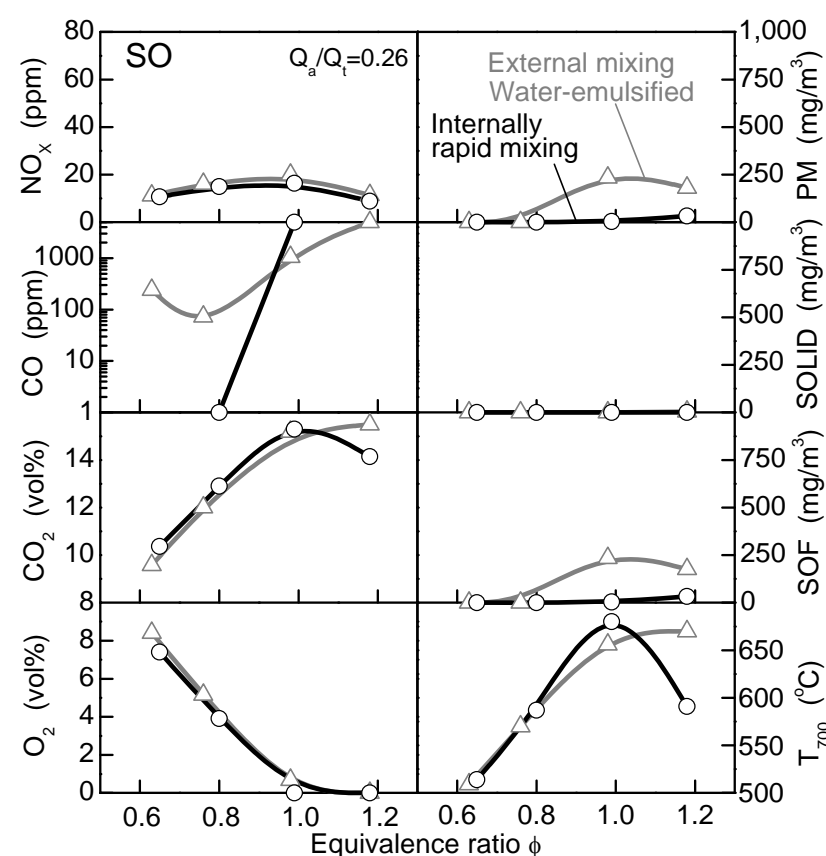

Fig. 4 Comparison of emissions between two types of injector (fuel: soybean with water-mixing or water-emulsified, water $50 \%$ ).

$\mathrm{T}_{700}$ at $\phi=1.2$ using external mixing type of injector is resulted by high flame height caused by inactive combustion.

Fig. 5 provides example of flame images at high load condition of $\phi=1.2$ using gas oil as fuel. Considering that bright flame is mainly luminescence of soot, water addition by both emulsified and water mixing has strong effect on soot reduction. In particular, internally rapid mixing injector shows less luminous and more transparent flame in the case of introducing water. These kinds of flame characteristics correspond to PM emissions shown in Figs. 3 and 4.

\subsection{Effects of Combustion Parameters on Emissions with Fuel-Water Internally Rapid Mixing}

Next, emission characteristics of internally rapid mixing type injector were investigated with changing experimental parameters such as equivalence ratio, atomizing air flow rate, water flow rate and fuel type.

Fig. 6 shows the effects of water content on emissions. Base fuel is soybean oil and air flow ratio of atomizing air to total air is kept constant at 0.26 . Water flow ratios against total fuel flow (soybean oil + water)

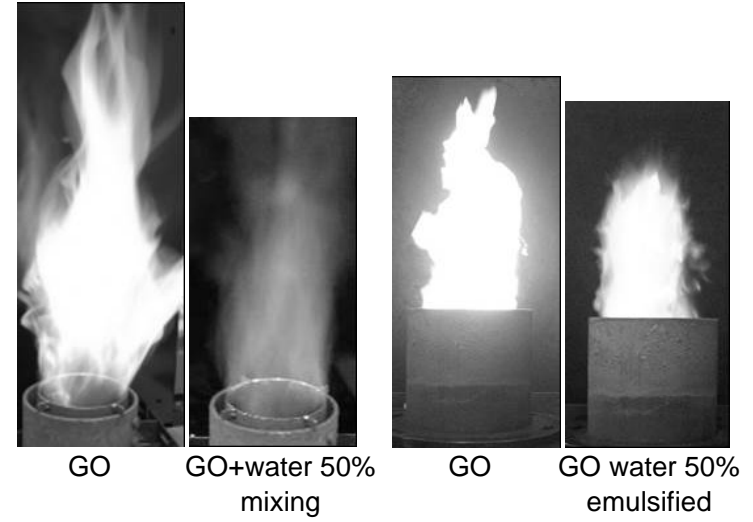

(a) Internally rapid mixing (b) External mixing

Fig. 5 Comparison of flames $(\phi=1.2)$.

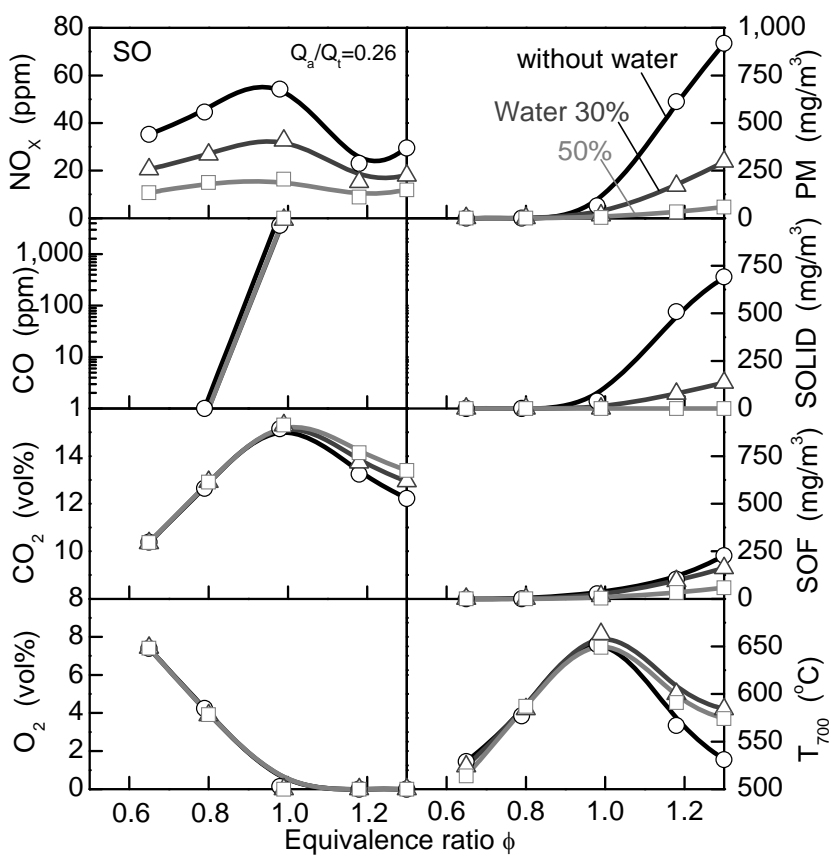

Fig. 6 Effects of water content on emissions.

are $0 \%, 30 \%$ and $50 \%$ in volume. In the figure, $\mathrm{NO}_{\mathrm{x}}$ is highest at equivalence ratio of around 1.0 as well as high gas temperature $T_{700}$ regardless of water content. Moreover, $\mathrm{NO}_{\mathrm{x}}$ emission is strongly dependent on water content. It is remarkable that high water content leads to low PM emissions even at high load of $\phi>0.9$. Excessive fuel is converted into CO, SOLID and some unburned is emitted as SOF. Large amount of water content in fuel is considered to produce more $\mathrm{CO}$ and less SOLID. This may be caused by the reaction named hydro-gaseous reaction bellow:

$$
\mathrm{C}+\mathrm{H}_{2} \mathrm{O} \rightarrow \mathrm{CO}+\mathrm{H}_{2}
$$



Injector on the Concept of Fuel-Water Internally Rapid Mixing

Carbon, which represents SOLID, in the above reaction is converted into $\mathrm{CO}$ and hydrogen. This may be one of the contributors on reduction of PM by introduction of water.

Fig. 7 investigates effects of atomizing air flow rate by changing $Q_{a} / Q_{t}$ from 0.18 to 0.44 . In this experiment, total air flow rate $Q_{t}$ was kept constant. Water content affects both $\mathrm{PM}$ and $\mathrm{NO}_{\mathrm{x}}$ emission. On the other hand, $Q_{a} / Q_{t}$ affects PM emission only.

Increase of $Q_{a} / Q_{t}$ without water (W0) results in lower PM emission. Increase of atomizing air flow rate facilitates fuel atomization; furthermore, it supplies larger amount of oxygen into the flame stabilizer. These factors promote combustion, leading to PM reduction. Under the condition that produces large amount of PM, rapid mixing of fuel and air has great effect on PM reduction. When the $Q_{a} / Q_{t}$ is lowered up to 0.18 , increase of fuel flow rate causes misfire due to insufficient supply of atomizing air.

On the other side, less effects of $Q_{a} / Q_{t}$ are shown in the case of $30 \%$ water (W30) and 50\% water (W50) as compared with the case of W0. These results imply that introducing water has larger effect on reduction of PM than enlarging $Q_{a} / Q_{t}$.

Fig. 8 shows the effect of fuel type on emissions. The figures compare two fuels, SO (soybean oil) and $\mathrm{GO}$ (gas oil). In the case of SO without water (W0), the exhaust gas contains high level of PM at high equivalence ratio as compared with GO. High viscosity on soybean oil of $74.78 \mathrm{~mm}^{2} / \mathrm{s}$ against gas oil of $4.08 \mathrm{~mm}^{2} / \mathrm{s}$ may cause insu fficient mixing of fuel and air even using internally rapid mixing type injector. However, as seen from the figures of W30 and W50, water addition makes difference in emissions between the fuels small. As mentioned above, high exhaust level of PM from soybean oil in W0 case may be caused by high viscosity of fuel. This also says less difference of PM emissions between fuels in W30 or W50 cases may be caused by the cancellation of the negative effect of high viscosity of soybean oil by adding water into fuels. It should be noted that adding water into fuel as emulsified form often results in significant increase in viscosity, for example water-emulsified soybean oil (water content, 30\%) of $500.85 \mathrm{~mm}^{2} / \mathrm{s}$ against neat soybean oil of $74.78 \mathrm{~mm}^{2} / \mathrm{s}$. Therefore, in the case of using emulsified fuel, high viscosity has bad influence on fuel atomization and fuel-air mixing, consequently results in poor combustion and heavy emissions [5]. Inversely, internally rapid mixing type of injector has great advantage for introduction of water into combustion field avoiding deterioration of combustion due to increase of fuel viscosity.

Fig. 9 illustrates emission performance of internally rapid mixing type of injector using soybean oil. The experimental parameters are fuel flow rate, $Q_{f}$, water flow rate, $Q_{w}$ and volumetric content of water against total fluid volume including fuel and water. The value of $Q_{a} / Q_{t}$ is kept constant. The injector has misfire limit at $\phi=0.6$ and $Q_{w}=0$. The misfire limit moves to higher equivalence ratio as water content increases.

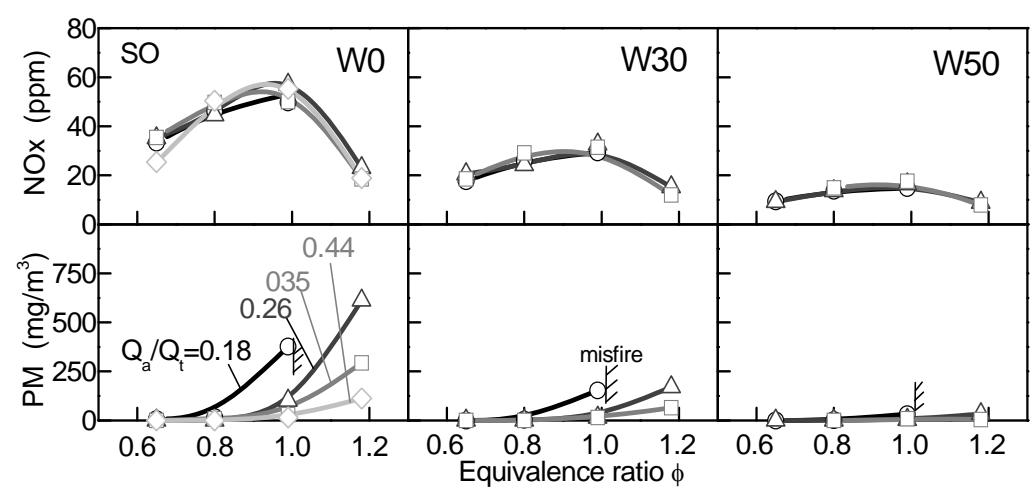

Fig. 7 Effects of atomizing air ratio on emissions with changed water content. 


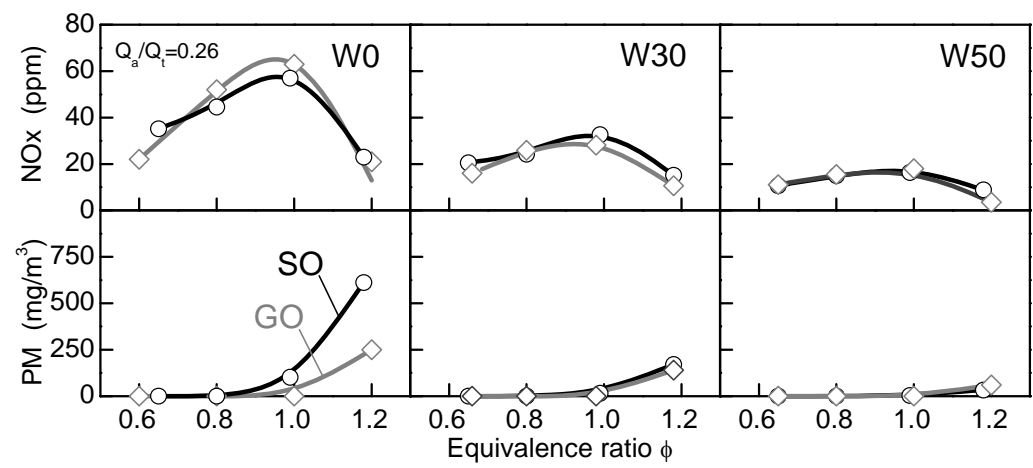

Fig. 8 Effects of fuel type on emissions with changed water content.

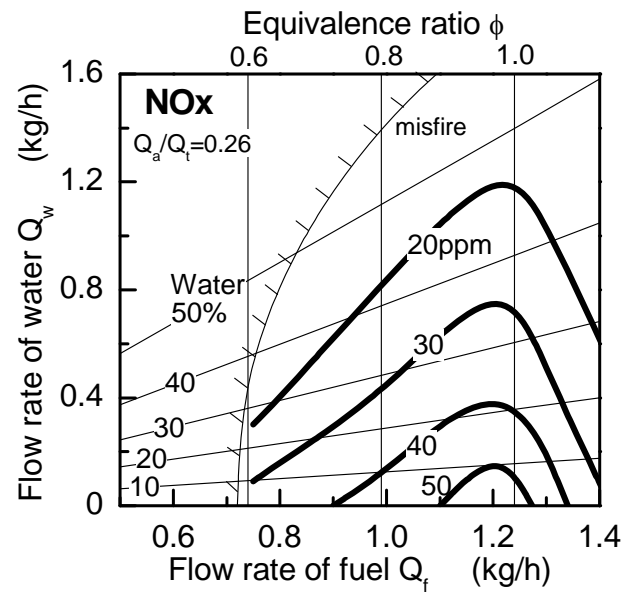

(a) $\mathrm{NO}_{\mathrm{x}}$

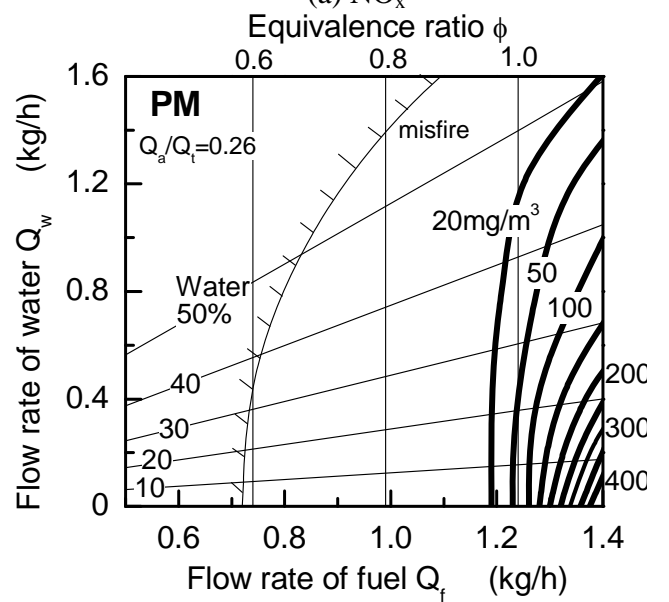

(b) PM

Fig. 9 Emission efficiency of internally rapid mixing injector (fuel: soybean oil).

The $\mathrm{NO}_{\mathrm{x}}$ contour lines in Fig. 9a show peak level at equivalence ratio, $\phi$, from 0.9 to 1.0 under any value of $Q_{w}$. $\mathrm{NO}_{\mathrm{x}}$ decreases with increase of water content. According to PM contour in Fig. 9b, soybean oil can be burnt with smokeless at equivalence ratio less than about 0.9. At higher equivalence ratio than 0.9, PM increases dramatically without water $\left(Q_{w}=0\right)$. Introducing water has great effect on reduction of PM for soybean oil. For example, the PM contour line of 20 $\mathrm{mg} / \mathrm{m}^{3}$ is extended to higher load of $\phi=1.1$ at water content of $50 \%$, although the line is limited at $\phi=0.95$ without water of $Q_{w}=0$.

Next, PM generation at high load condition, $\phi=1.2$ to $Q_{t}$, is further investigated from the experimental data partially shown in Fig. 8. Fig. 10 shows PM index, EIPM, against some characteristics such as equivalence ratio, $\phi_{\mathrm{a}}$ inside of the flame stabilizer (Fig. 10a), spray velocity, $V_{a}$ at outlet of injector (Fig. 10a) and water content (Fig. 10b). The EIPM is mass ratio of exhaust PM to supplied fuel. The $\phi_{\mathrm{a}}$ is local equivalence ratio inside of the flame stabilizer calculated based on the mass flow ratio of supplied fuel to atomizing air, where air inside of the flame stabilizer is assumed to be supplied only by atomizing air; namely secondary-air flow into the flame stabilizer is neglected. The $V_{a}$ is simply calculated by atomizing air flow rate and total spray hole-area of the injector. $\phi_{a}$ and $V_{a}$ are inversely related each other.

Fig. 10a shows the effects of $\phi_{\mathrm{a}}$ and $V_{a}$ on EIPM. EIPM depends on $\phi_{\mathrm{a}}$ almost linearly at every condition despite fuel type. The spray velocity $V_{a}$ is also related to EIPM. These tendencies imply that both $\phi_{\mathrm{a}}$ and $V_{a}$ may be the key factors for PM generation. The tendency of PM generation on $\phi_{\mathrm{a}}$ may indicate that initial burning environment in flame stabilizer has strong influence on PM generation. The tendency of 


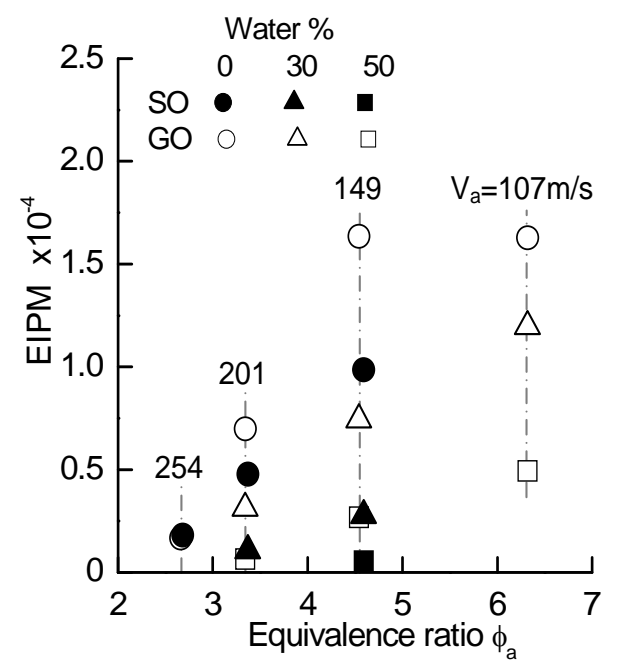

(a) Effect of equivalence ratio and injection velocity in flame stabilizer

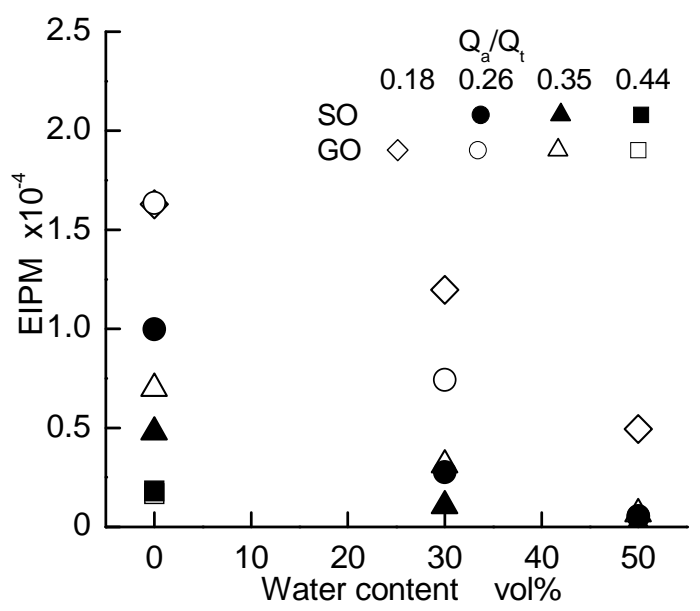

(b) Effect of water content

Fig. 10 Characteristics of PM emission.

$V_{a}$ may represent that strong jet from the injector promotes atomization and mixing, which reduce PM generation effectively.

Fig. 10b suggests that water supply is effective to reduce PM. Reduction of PM in soybean oil by water supply is more sensitive than gas oil. For example, in the case of $Q_{a} / Q_{t}=0.26$, adding $30 \%$ of water reduces $\mathrm{PM}$ to $1 / 4$ of $0 \%$ of water in SO, as compared with PM reduction of 1/2 in GO. Absolute EIPM reduction in this case is approximately consistent between SO and GO. In addition, PM reduction is more remarkable against the variation of water content from $0 \%$ to $30 \%$ rather than from $30 \%$ to $50 \%$. This result indicates high content of water nearly $50 \%$ is effective in reduction of $\mathrm{NO}_{\mathrm{x}}$ rather than that of PM.

\section{Conclusions}

This study has developed a new burner injector with less $\mathrm{PM}$ and $\mathrm{NO}_{\mathrm{x}}$ at high load condition by adding water. Fuel and water are mixed rapidly by atomizing air in the small mixing chamber installed in the injector, and three-fluids consists of fuel, water and air are injected into a flame stabilizer of the burner. The series of experiments were examined by using soybean oil and gas oil as fuel. Combustion performance of this injector is summarized as follows:

(1) The internally rapid mixing type of injector is useful technique to introduce water into burner combustion. The injector emits less PM at high load of equivalence ratio over 0.9 as compared with the external mixing type of injector. $\mathrm{NO}_{\mathrm{x}}$ emission is strongly dependent on water flow rate;

(2) Larger amount of water addition leads to less PM emissions as well as $\mathrm{NO}_{\mathrm{x}}$ emission at high load. $30 \%$ of adding water results in significant reduction in PM emission. However, additional $20 \%$, i.e., $50 \%$ of water, causes less effect as compared to initial 30\%;

(3) In opposition to high SOF emissions at high load condition by using water-emulsified fuel, combustion by the internally rapid mixing injector produces less SOF even in the case of adding water;

(4) Adding water by using water-emulsified fuel results in higher CO emission in whole load condition. On the contrary, adding water by the internally rapid mixing injector produces less CO emission in low load condition;

(5) Three-fluids mixing can avoid the problem of the increase of fuel viscosity that is generally occurred in case of fuel- water- emulsification;

(6) Mixing conditions inside of the flame stabilizer are important for PM reduction as well as in the mixing chamber of the injector. Higher injection velocity and lower equivalence ratio inside the flame stabilizer are effective to PM reduction. 


\section{Acknowledgments}

The authors would like to thank Mr. Nakagawa, Mr. Kumura and Mr. Uchihara who are formerly and present graduate students of the University of Tokushima, for their contribution to this research.

\section{References}

[1] S.R. Gollahalli, An experimental study of the combustion of unsupported drops of residual oils and emulsions, Combustion Science and Technology 19 (5) (1979) 245-250.

[2] J.C. Lasheras, A.C. Fernandez-Pello, F.L. Dryer, Initial observations on the free droplet combustion characteristics of water-in-fuel emulsions, Combustion Science and Technology 21 (1) (1979) 1-14.

[3] Y. Mizutani, A. Taki, Burning and emission characteristics and combustion mechanisms of wter-in-oil-emulsion sprays: 1st report, properties of emulsions and their burning and emission characteristics, J.
JSME (B) 47 (424) (1981) 2379-2385.

[4] H. Hiroyasu, M. Arai, K. Nishida, The combustion of water-in-heavy oil emulsions: 1st report, combustion characteristics of emulsion sprays, J. JSME (B) 48 (430) (1985) 1182-1188.

[5] T. Yatsufusa, T. Kumura, Y. Nakagawa, Y. Kidoguchi, Advantage of using water-emulsified fuel on combustion and emission characteristics, in: ECM2009, Hong Kong, 2009.

[6] Y. Yoshimoto, M. Tsukahara, T. Murayama, Studies on the microexplosion of emulsified fuels: 1st report, effects of fuel properties, water contents and particle sizes on the microexplosion on a hot surface, J. JSME (B) 55 (519) (1989) 3538-3543.

[7] Y. Xu, C.G. Zhu, Y.B. Shen, D. Poulikakos, Holographic investigation of microexplosion in an emulsified diesel oil spray, Atomization and Sprays 3 (2) (1993) 193-202.

[8] Y. Mizutani, M. Fuchihata, Y. Matsuoka, M. Muraoka, Observation of micro-explosion in spray flames of light oil-water emulsions, J. JSME (B) 66 (646) (2000) 1544-1549. 